\title{
Erratum to: Machine Learning-Based Investigation of the Associations between CMEs and Filaments
}

\author{
M. Al-Omari · R. Qahwaji • T. Colak • S. Ipson
}

Published online: 25 October 2012

(C) Springer Science+Business Media Dordrecht 2012

Erratum to: Solar Phys (2010) 262:511-539

DOI 10.1007/s11207-010-9516-5

This article was published with an erroneous version of the title and running title. Please find the correct version of the article title on this page, which should be regarded as the final version by the reader.

The online version of the original article can be found under doi:10.1007/s11207-010-9516-5.

M. Al-Omari · R. Qahwaji $(\bowtie) \cdot$ T. Colak · S. Ipson

School of Computing, Informatics \& Media, University of Bradford, Richmond Road, BD7 1DP, Bradford, England, UK

e-mail: r.s.r.qahwaji@ bradford.ac.uk

M. Al-Omari

e-mail: m_alomari@asu.edu.jo

T. Colak

e-mail: t.colak@brad.ac.uk

S. Ipson

e-mail: s.s.ipson@ brad.ac.uk 